\title{
Performance Analysis of AP1000 Passive Systems during Direct Vessel Injection (DVI) Line Break
}

\author{
A.S. Ekariansyah ${ }^{\star}$ and S. Widodo \\ Center for Nuclear Reactor Technology and Safety, National Nuclear Energy Agency \\ Puspiptek Area, Serpong, Tangerang 15314, Indonesia
}

\section{ARTICLE INFO}

\section{Article history:}

Received 2 November 2015

Received in revised form 19 April 2016

Accepted 25 April 2016

Keywords:

Direct vessel injection (DVI) break

AP1000

RELAP5 code

\begin{abstract}
A B S T R A C T
Generation II Nuclear Power Plants (NPPs) have a design weakness as shown by the Fukushima accident. Therefore, Generation III+ NPPs are developed with focus on improvements of fuel technology and thermal efficiency, standardized design, and the use of passive safety system. One type of Generation III+ NPP is the AP1000 that is a pressurized water reactor (PWR) type that has received the final design acceptance from US-NRC and is already under construction at several sites in China as of 2015. The aim of this study is to investigate the behavior and performance of the passive safety system in the AP1000 and to verify the safety margin during the direct vessel injection (DVI) line break as selected event. This event was simulated using RELAP5/SCDAP/Mod3.4 as a best-estimate code developed for transient simulation of light water reactors during postulated accidents. This event is also described in the AP1000 design control document as one of several postulated accidents simulated using the NOTRUMP code. The results obtained from RELAP5 calculation was then compared with the results of simulations using the NOTRUMP code. The results show relatively good agreements in terms of time sequences and characteristics of some injected flow from the passive safety system. The simulation results show that the break of one of the two available DVI lines can be mitigated by the injected coolant flowing, which is operated effectively by gravity and density difference in the cooling system and does not lead to core uncovery. Despite the substantial effort to obtain an apropriate AP1000 model due to lack of detailed geometrical data, the present model can be used as a platform model for other initiating event considered in the AP1000 accident analysis.
\end{abstract}

\section{INTRODUCTION}

The pressurized water reactor (PWR) is the most commonly constructed type of nuclear power plant (NPP) in the world. From a total of 435 plants in the world, 270 of them $(61 \%)$ are PWRs, contributing $67 \%$ of world's nuclear electricity output [1]. All operating PWRs are from Generation II that were built no later than 1990s; part of their general specification is their dependency on active components and systems. In terms of safety, the availability of safety systems in Generation II plants is dependent on external AC power supply.

\footnotetext{
* Corresponding author.

E-mail address: andi_se@batan.go.id

DOI: http://dx.doi.org/10.17146/aij.2016.511
}

The plants' vulnerability has been shown in the Fukushima incident in 2011; while the accident occurred with boiling water reactors (BWRs), PWRs share the same vulnerability. NPP designers already realized this design weakness before the Fukushima accident and have already introduced the Generation III NPP that is focused on improvement of fuel technology, improvement of thermal efficiency, standardized design, and the use of passive safety system.

Currently, there are two types of Generation III PWR, namely the Advanced PWR (APWR) developed by Mitsubishi Heavy Industries and planned to be constructed in the Tsuruga site of Japan, and the ATMEA1 by AREVA and Mitsubishi. A further development of Generation III 
are the Generation III+ designs, which include improvements in safety and economical aspect, and of which currently there are five types available, namely AP1000, European Pressurized Reactor (EPR), APR-1400, US-APWR, and VVER-1200. The Advanced PWR 1000 (AP1000) from Westinghouse Electric Company had received the final design approval from US-NRC in 2005 [2] and has become one of the best choices for the next generation of nuclear power plants to be constructed in China [3]. A contract has also been signed to build four South Korean APR-1400 units in the United Arab Emirates [4].

From the various types of Generation III+ NPPs, this study has selected the AP1000 as the advanced PWR based on two reasons. First, after the Fukushima accident, the research on passive dependent safety features has been significantly increased as one of the solutions against the weakness of Generation II reactors. Second, the AP1000 design is based on proven design and is already under construction process in China. Those two considerations are advantageous when the Indonesian Government Regulation No. 2 / 2014 concerning Nuclear Installation Licensing and Nuclear Material Utilization is considered. The regulation requires that the future NPP in Indonesia should be selected based on proven technology for all its structures, systems, and components important for safety. The aim of this study is to investigate the behavior and performance of the passive safety system in the AP1000 and to verify the safety margin during the direct vessel injection (DVI) line break as the selected event. This event was also selected due to the importance of the DVI line for discharging the injected flow directly into the pressure vessel; thus, its breakage will result in a great challenge to the passive safety system and is determined as the greatest contribution to the core damage frequency [5]. This event was simulated using RELAP5/SCDAP/Mod3.4 as a best-estimate code developed for transient simulation of light water reactor during a postulated accident. This event is also described in the AP1000 design control documents, Chapter 15: Accident Analyses, issued by Westinghouse, as one of several postulated accidents simulated using different best-estimate codes [6]. In that document, the DVI line break event was simulated using the NOTRUMP computer code. The verification of the results will be performed by comparing the RELAP5 simulation with the NOTRUMP for several thermal hydraulics parameters. Similar research has been done by Xue-Dong Qiao et al. regarding the DVI line break simulation using RELAP5 [7]. Several key parameters have been also compared with the results from using the NOTRUMP code. The differences between the aforementioned study and this one are that here more thermal hydraulic parameters have been retrieved and compared, such as core mixture water level and core cladding temperature, to show more deeply the performance of the AP1000 passive safety system, to ensure the safety of the AP1000.

\section{THEORY}

\section{AP1000 passive safety systems}

The AP1000 passive safety system consists of the passive core cooling system (PXS) and the passive containment cooling system (PCS). The PXS is then subdivided into the passive residual heat removal system (PRHRS), the passive safety injection system (PSIS), and the automatic depressurization system (ADS) to provide core decay heat removal, safety injection for core cooling, and reactor coolant system (RCS) depressurization [8]. The combination of all the three systems will protect the AP1000 reactor against leakages and ruptures of various sizes and in various locations. This study only focuses on the function of the PXS rather than the PCS due to the PCS's role in the longterm cooling process after an accident. The description of PXS subsystem and associated components are as follows:

\section{Passive residual heat removal system (PRHRS)}

The main component of the PRHRS is the passive residual heat removal heat exchanger (PRHR-HX) that is designed to operate without active components but instead depend on passive components and processes such as gravity effects and natural circulation [9]. The PRHR-HX features a C-shaped tube bundle as a component for transferring the core decay heat and is immersed inside the in-containment refueling water storage tank (IRWST) as heat sink (see Fig. 1). The function of the PRHRS is specifically needed for certain postulated accidents where the cooling process via the steam generators is unavailable. 


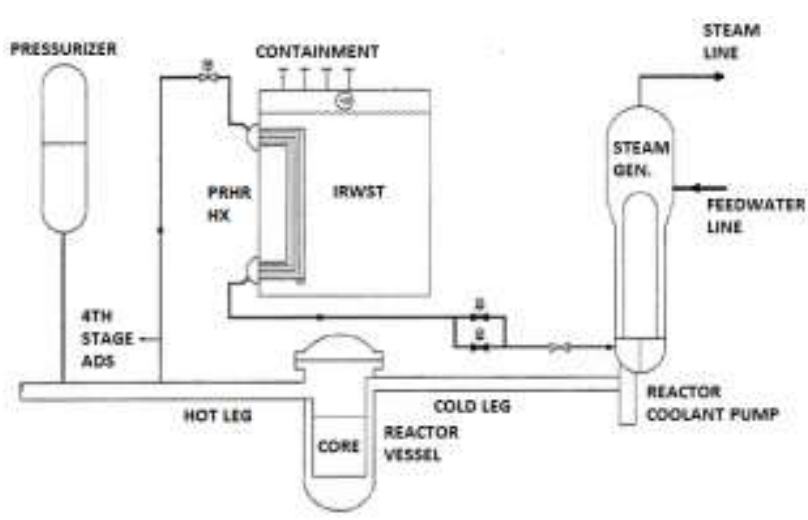

Fig. 1. Schematic diagram of passive residual heat removal system (PRHRS) [5].

\section{Passive safety injection system (PSIS)}

The main component of the PSIS are two core makeup tanks, two accumulators, one IRWST, and one containment sump, as shown in Fig. 2. The core makeup tank (CMT) systems will provide a relatively high flowrate of borated water for a longer time at any pressure. The accumulators provide a higher flowrate of borated water for a short time when the RCS pressure falls under $4.83 \mathrm{MPa}$, allowing the nitrogen pressure inside the accumulator to push the accumulator's content out. The IRWST will provide a low flowrate of borated water for a longer time when the RCS pressure decreases to nearly the containment pressure or the pressure of the tank. The containment sump will recirculate the borated water from the above three sources to the RCS for a continuing core cooling process. All PSIS functions work via a direct vessel injection line to reach the core inside.

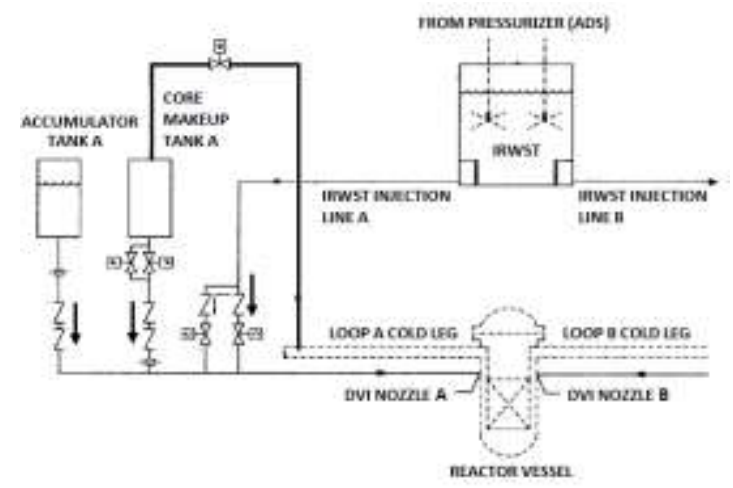

Fig. 2. Schematic diagram of passive safety injection system (PSIS) showing one of the two lines [8].

\section{Automatic depressurization system (ADS)}

The ADS consists of two trains of four stages of valves, as shown in Fig. 3. It is actually a part of the RCS, where the first three stages of valves are connected to the pressurizer steam space to discharge the steam to the water inside the IRWST through spargers. The fluid (steam or two-phase mixture) from the fourth-stage valves that are connected to the two hot legs is vented directly to the contaiment atmosphere. Those ADS valves open in sequence based on the CMT water level to provide a controlled depressurization of the RCS, specifically during a small-break LOCA in order to achive an RCS pressure condition for injection from accumulator and IRWST.

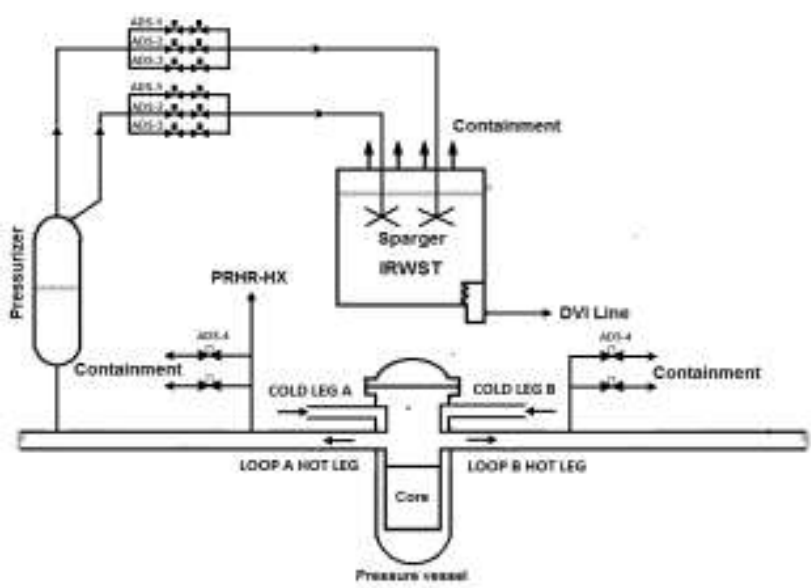

Fig. 3. Simplified schematic diagram of automatic depressurization system (ADS) [8].

\section{DVI line break accident}

A DVI line break is defined as a doubleended rupture of the pipe close to the DVI nozzle (see Fig. 2), meaning that effectively two breaks should be modeled. From two DVI nozzles, only one break line is assumed to be analyzed [6]. The two breaks cause two sources of coolant discharge to be considered. One source in the vessel side will lead to reactor depressurization, and the other source to actuation of broken line accumulator and CMT to discharge coolant into the containment. Therefore, only one out of the two PSISes will have a role to respond the break sequences.

\section{METHODOLOGY}

In this study, the primary, secondary, and passive safety systems of AP1000 were modeled first. A steady-state calculation was performed in order to obtain the steady-state operation condition. After that, the DVI line break simulation was conducted and the reactor system behavior during the event was analyzed; the behavior includes, among others, reactor coolant system (RCS) depressurization, inventory depletion, and inventory refilling via safety injection. The results of analysis from the AP1000 design control documents were used as comparison with the results obtained during 
the analysis in this study. From that comparison, the accuracy of the AP1000 model developed for this simulation can also be analyzed, and the results are useful as a tool to verify the results from other analyses.

\section{RELAP5 model for AP1000}

In order to simulate the event, a model of the AP1000 should be developed. The development of an AP1000 model using RELAP5 was carried out in several stages, starting with the model of primary loop, followed by partial secondary loop, and finally by each part of the passive safety system. During each model's development, a verification and validation process was performed, resulting in several improvements and modifications. The model of primary and secondary loops has been described in reference [10] and has been continuously modified since then. In general, the primary loop consists of one hot leg, two cold legs, one steam generator, one pressurizer, and two canned motor pumps. The secondary loop is modeled as a downcomer connected to the main feedwater source; the downcomer carries the water to be boiled inside the boiling region. The resulting vapor-water is separated using the separator model, and the end dry steam is directed into a steam dome and one control volume representing the turbine region. As a part of the primary loop, the reactor pressure vessel (RPV) is modeled as a circuit of hydraulic components, such as downcomer, bottom head, lower plenum, core active region, core bypass, upper plenum, and upper head, to show the coolant flow direction. The core active region is subdivided into two flow channels representing the hot and average channel inside the fuel with different radial heat fluxes and channel flow. Each core channel is composed of nine axial segments corresponding to the number of spacer grids of fuel assembly.

The modeling of PXS, consisting of PRHRS, CMT, and IRWST, and containment system with its cooling system (PCS), has been carried out step by step as described in the references [11-13]. E. B. Shi et al. described the utilization of those PXS components to anticipate the station blackout event in an AP1000 [14]. Figure 4 shows the most recent model of the AP1000 prepared for this particular event analysis, written in the RELAP5 input deck. The model of the PRHR-HX is similar to the model of steam generator in the primary tubes side, where hundreds of heat ransfer tubes are lumped into a single component with a similar calculated heat transfer area. Those tubes are connected to the IRWST model using a heat structure model to enable the heat transfer from the primary side into the IRWST pool water model. The IRWST pool water is modeled as several vertical hydrodynamic volumes with an air space in the top connected into the containment model. To model the PSIS, a loop model consisting of the CMT, the accumulator, and the DVI line is developed. The CMT tank is modeled as several vertical hydrodynamic volumes with an outlet valve as a trip valve in the bottom of CMT injection line. The accumulator is added at the last step of the development process as a lumped component containing nitrogen gas with a pressure of $4.83 \mathrm{MPa}$.

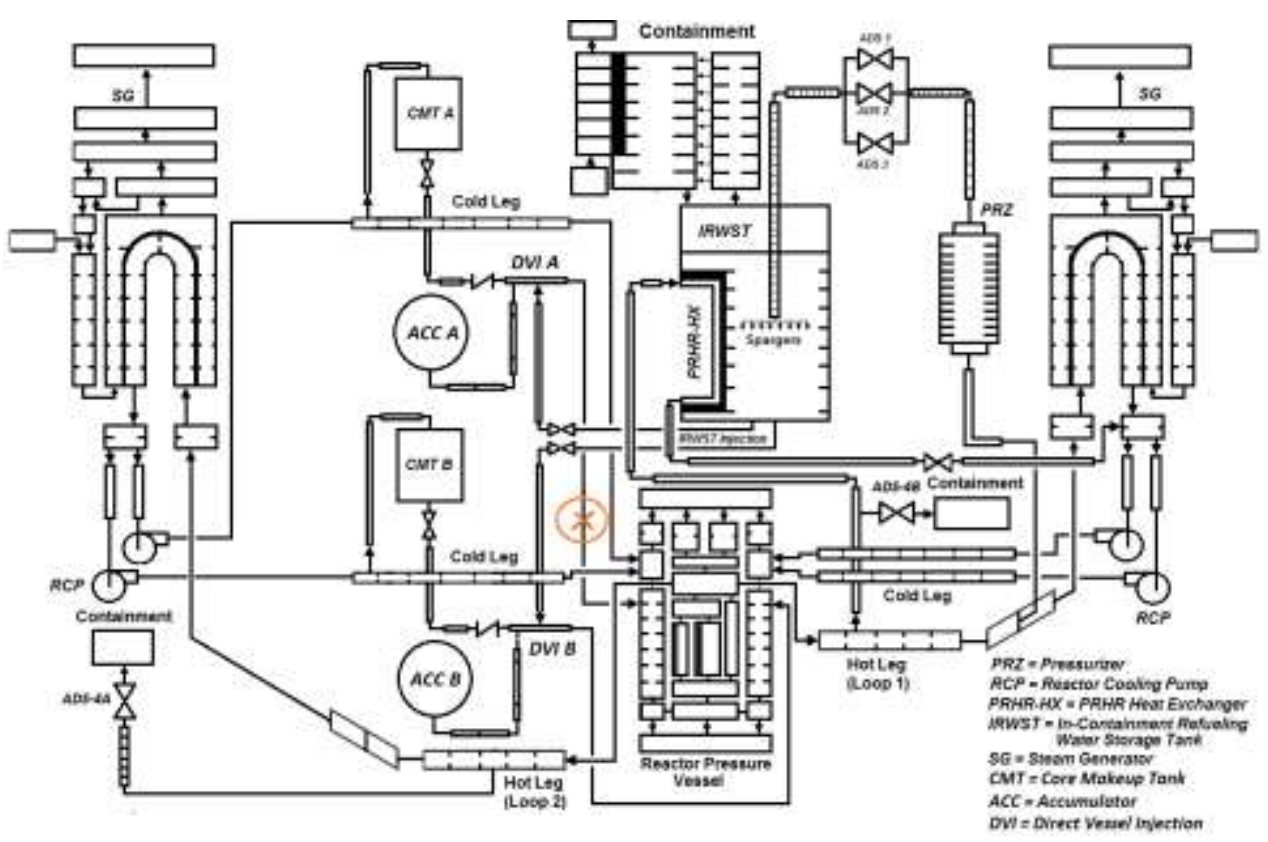

Fig. 4. AP1000 nodalization using RELAP5 for accident analysis and the DVI break location (X). 
The DVI line break event requires the actuation of the ADS; therefore, the first three stages of the ADS are modeled by three parallel pipes connected to the pressurizer's upper head. Each flow path has one motor valve with a flow area similar to two valves controlled by open and close trip in the input deck. The two stage-four ADSes are modeled as two trip valves connected to the two hot legs respectively. The functionality of the ADS model has been verified and described in [15] and [16].

\section{Modelling of the DVI line break}

The DVI line break occurs in one of two DVI lines connecting the pressure vessel. The exact location is in the inlet nozzle directing the injected coolant into the downcomer (The " $X$ " sign in Fig. 4). To simulate the break, a 6.81-inch DVI line break, which represents a double-ended break, is added to the input deck by adding two trip valves with their associated flow areas and a time-dependent volume as the discharge volume.

Table 1. PMS setpoints and time delay used in the DVI line break analysis

\begin{tabular}{|c|c|c|}
\hline Function & $\begin{array}{l}\text { Setpoint assumed in } \\
\text { the event }\end{array}$ & $\begin{array}{l}\text { Time } \\
\text { delays (sec) }\end{array}$ \\
\hline $\begin{array}{l}\text { Reactor trip on low } \\
\text { pressurizer pressure }\end{array}$ & $12.41 \mathrm{MPa}$ & 2.0 \\
\hline $\begin{array}{l}\text { "S" signal on low-low } \\
\text { pressurizer pressure }\end{array}$ & $11.72 \mathrm{MPa}$ & 2.0 \\
\hline $\begin{array}{l}\text { SG feedwater control } \\
\text { valves starts to close }\end{array}$ & After " $S$ " signal & 2.0 \\
\hline $\begin{array}{l}\text { Main steam isolation } \\
\text { valves start to close }\end{array}$ & $\begin{array}{l}\text { After reactor trip } \\
\text { signal }\end{array}$ & 6.0 \\
\hline $\begin{array}{l}\text { Reactor coolant } \\
\text { pumps trip }\end{array}$ & After "S" signal & 6.0 \\
\hline $\begin{array}{l}\text { PRHRS isolation } \\
\text { valve starts to open }\end{array}$ & After " $S$ " signal & 62.0 \\
\hline CMT injection starts & After " $S$ " signal & 2.0 \\
\hline $\begin{array}{l}\text { ACC injection starts } \\
\text { on low RCS pressure }\end{array}$ & $4.83 \mathrm{MPa}$ & 0.0 \\
\hline $\begin{array}{l}\text { ADS- } 1 \text { control valve } \\
\text { trip signal }\end{array}$ & $\begin{array}{l}67.5 \% \text { liquid } \\
\text { volume fraction in } \\
\text { CMT }\end{array}$ & 20.0 \\
\hline $\begin{array}{l}\text { ADS- } 2 \text { control valve } \\
\text { trip signal }\end{array}$ & $\begin{array}{l}70 \mathrm{~s} \text { after ADS-1 } \\
\text { actuation }\end{array}$ & 0.0 \\
\hline $\begin{array}{l}\text { ADS- } 3 \text { control valve } \\
\text { trip signal }\end{array}$ & $\begin{array}{l}120 \mathrm{~s} \text { after } \mathrm{ADS}-2 \\
\text { actuation }\end{array}$ & 0.0 \\
\hline ADS-4A starts to open & $\begin{array}{l}120 \mathrm{~s} \text { after ADS-3 } \\
\text { actuation }\end{array}$ & 0.0 \\
\hline ADS-4B starts to open & $\begin{array}{l}60 \mathrm{~s} \text { after } \mathrm{ADS}-4 \mathrm{~A} \\
\text { actuation }\end{array}$ & 0.0 \\
\hline $\begin{array}{l}\text { IRWST isolation } \\
\text { valve starts to open }\end{array}$ & $\begin{array}{l}120 \mathrm{~s} \text { after ADS-3 } \\
\text { actuation }\end{array}$ & 0.0 \\
\hline
\end{tabular}

A double-ended break requires a model of break discharge from two directions, namely the DVI side and the downcomer side, as modeled by those two trip valves. Each downward-oriented trip valve employs models of the counter-current flow limitation (CCFL), choked flow, and abrupt area change. After the break occurs, the AP1000 Protection and Monitoring System (PMS) detects any anomaly and change of the reactor parameters and send the related signal to actuate the reactor protection system and safety system related to the event. Table 1 lists the PMS setpoints and time delay assumptions used in the DVI linebreak LOCA as summarized from the AP1000 design control document of Chapter 15: Accident Analyses [6].

\section{RESULTS AND DISCUSSION}

\section{Steady-state simulation}

Before the break is simulated, a steady-state condition should be achieved, representing the initial conditions of the plant. The duration of simulation needed to achieve that condition varies depending on the needed accuracy of parameters. Some parameters needed to achieve the steady-state condition, obtained as a result of $1000 \mathrm{~s}$ of simulation, are summarized in Table 2.

Table 2. Steady-state calculated results of AP1000

\begin{tabular}{lll}
\hline Reactor Parameters & RELAP5 & Rated value \\
\hline Core thermal power (MWt) & 3468.00 & 3400.00 \\
& $(102 \%)$ & $(100 \%)$ \\
Vessel inlet / outlet temperature & 292.13 / & 280.67 / \\
$\left({ }^{\circ} \mathrm{C}\right)$ & 327.00 & 323.33 \\
RCS pressure (MPa) & 15.69 & 15.45 \\
Hot / cold leg mass flow & $8539.12 /$ & $8743.2 /$ \\
(kg/sec) & 4269.36 & 4397.3 \\
Hot / cold leg coolant flow & $46529.35 /$ & $44458.21 /$ \\
$\left(\mathrm{m}^{3} /\right.$ hours) & 20674.72 & 21566.26 \\
Total steam flow (2 steam & 1929.34 & 1887.44 \\
generators) (kg/sec) & & \\
$\begin{array}{l}\text { Steam generator pressure (MPa) } \\
\text { Steam generator feed water }\end{array}$ & 6.06 & 5.76 \\
temperature $\left({ }^{\circ} \mathrm{C}\right)$ & 226.67 & 226.67 \\
$\begin{array}{l}\text { Feed water mass flow (kg/sec) } \\
\text { Transferred heat from RCS to }\end{array}$ & 965.00 & 943.72 \\
secondary side (core power plus & & 3415.0 \\
RCP heat) (MWt) & & \\
Pressurizer water level (m) & 6.61 & 6.53 \\
\hline
\end{tabular}

The rated values are the design parameters obtained from the Chapter 5: Reactor Coolant System and Connected Systems from the AP1000 design control document [6]. Table 2 shows the comparison between the steady-state calculated values from RELAP5 code and the rated values for the AP1000 plant. The difference in the core thermal power of RELAP5 arises from increased thermal power to $2 \%$ above the rated value as required by the accident 
conditions. Those increased thermal power leads to the increases of several parameters, such as feedwater and steam mass flows, due to increased heat transferred from the RCS. For other parameters, there is a good agreement between the calculated values and the rated values. After $1000 \mathrm{~s}$ of steady-state simulation, a simulation of a doubleended break in the DVI-A line (see Fig. 4) with a 6.81 inch diameter is conducted by opening two trip valves, each connected to the DVI line A and the dedicated downcomer.

\section{Transient simulation}

The break is initiated by opening the break trip valve instantaneously at 0 seconds (after 1000 seconds is simulated in a steady-state simulation). In Fig. 4, the break trip valve is located in the DVIA line. In this case, there are two break sources, namely the broken DVI line and another source in the downcomer. From the DVI line side, the break will directly initiate an accumulator discharge via the DVI line to the containment. From the downcomer side, a subcooled discharge causes a rapid RCS depressurization until the pressure setpoint for reactor trip is reached. A reactor trip signal is generated, which initiates a shutdown process. That signal will also initiate a mechanism to isolate the main steam line in all two steam generators. As the RCS depressurization continues, the pressure setpoint for the "Safeguard" signal is reached causing several actuation of reactor control system and PXS. The "S" signal will actuate the main feedwater valve to close, cutting the feedwater supply to both of the two steam generators. After a different time delay, the reactor cooling pumps are also tripped, causing a loss of forced convection in the RCS. In the PXS, the opening of the CMT isolation valves allows the CMT in the broken loop to discharge directly to the containment via the break trip valve. Because of that discharge flow, the level of CMT is formed and starts to fall until the ADS stage 1 setpoint, corresponding to $67.5 \%$ tank volume, is reached, which inititates an opening of ADS stage 1 valves. That event will discharge steam from the top of the pressurizer leading an increase of RCS depressurization rate. The ADS stage 2 valves open 70 seconds after the opening of the ADS stage 1 valves. The opening of two first ADS stage valves accelerates the RCS depressurization, which affects the pressure in the intact DVI loop (DVI-B in Fig. 4). The intact loop accumulator starts to inject into the downcomer as the pressure falls below the accumulator pressure setting. The ADS stage 3 valves open 120 seconds after the opening of the ADS stage 2 valves followed by the ADS stage $4 \mathrm{~A}$ and $4 \mathrm{~B}$ valves to open after related time sequences. The IRWST injection line connected to the DVI loop is isolated by a valve, which initiates and opening, coincident with the ADS stage 3 valves open signal. An injection flow from the IRWST is not established as the RCS pressure is still above the IRWST pressure. In the broken DVI loop, once the DVI line pressure falls below the IRWST pressure, the water from the IRWST starts to discharge via the broken trip valve into the containment. In the intact DVI loop, the RCS depressurization continues after the opening of the ADS stage 4 valves, which allows an injection flow from the intact IRWST injection line to take place.

The event sequences described above for a duration of 3000 seconds are summarized in Table 3 for the simulation results; there, it is compared with the results from NOTRUMP code of AP1000 accident analysis document. The results listed in Table 3 show a relatively good agreement between RELAP5 and NOTRUMP code calculations. The differences on the event occurrence times are still within the range and acceptable due to the complexity of the model and the assumptions made. In the RELAP5 model, many assumptions are made regarding the lengths and heights of the injection line and other lines in the DVI loops, due to the unavailability of data; the assumptions affect the accuracy of event occurrence times of natural circulation and gravity-injected flow.

Table 3. Double-ended DVI line break sequence of events

\begin{tabular}{lll}
\hline Events & \multicolumn{2}{c}{ Time } \\
& RELAP5 & NOTRUMP \\
\hline Break at DVI-A nozzle opens & 0.0 & 0.0 \\
& $\begin{array}{l}(\mathrm{T}=1000 \\
\text { seconds) }\end{array}$ & \\
& 23.39 & 13.1 \\
Reactor trip signal (RCS & & \\
pressure < 12,411 MPa) & 29.13 & 18.5 \\
"S" signal (RCS pressure $<$ & & \\
11,72 MPa) & 29.39 & 19.1 \\
Main steam valves to close & 31.13 & 20.6 \\
Main feedwater valves to close & 35.13 & 24.6 \\
Reactor coolant pump trip & 201.73 & 182.5 \\
ADS stage 1 valves open & 271.73 & 252.5 \\
ADS stage 2 valves open & 299.00 & 254.0 \\
Intact accumulator (DVI-B) & & \\
injection starts & 304.07 & 372.5 \\
ADS stage 3 valves open & 513.71 & 492.5 \\
ADS stage 4 valves open & 674.00 & 600.0 \\
Intact accumulator (DVI-B) & & \\
empties & 850.00 & 1470.0 \\
Intact loop IRWST (DVI-B) & & \\
injection starts & 2103.50 & 2123.0 \\
Intact loop CMT (DVI-B) & & \\
empties & & \\
\hline
\end{tabular}

The sequences after the break can also be identified as the typical phases of the small break LOCA involving the operation of the passive 
engineered safety features. Those phases are the blowdown phase, the natural circulation phase, the ADS blowdown phase, and the IRWST injection phase [17]. The blowdown phase is characterized by the RCS depressurization up to a stable condition due to the loss of coolant mass. At the end of that phase, the water in the pressurizer is completely empty and replaced by the steam. The natural circulation phase is basically a core decay heat removal process by the steam generator's secondary side, PRHR-HX, and core makeup tank recirculation flow. The ADS blowdown phase is initiated by the opening of the first three stages of the ADS valves followed by the fourth stage ADS valves for a controlled depressurization of the RCS. In this phase, the RCS pressure is brought down to the actuation setting of the accumulator in the intact DVI line. The IRWST injection phase is the phase where the coolant from the IRWST starts to flow by gravity into the core via the DVI line. This can only be achieved when the RCS pressure is below the pressure in the top of the IRWST to initiate the long term core cooling.

Figures 5 to 10 show the results of several RELAP5 transient simulations and their comparisons with the NOTRUMP simulation results. It is to be noted that the NOTRUMP figures are extracted manually from the AP1000 design control document of Chapter 15: Accident Analyses, so that the accuracy of the transient simulation might not be high [6]. The calculated RCS depressurization transient and the actuation of the reactor protection system and PXS are shown in Fig. 5. Once the DVI-A line break occurs, the RCS pressure drops rapidly from the initial operating pressure of 155 bar to the pressure setpoint of the trip reactor and the "S" signal. At the end of the simulation time, the RCS pressure is stable around 1.3 bar. The pressure transients show a close similarity between the two codes. In the figure, the time event designation is referred to the RELAP5 transient line.

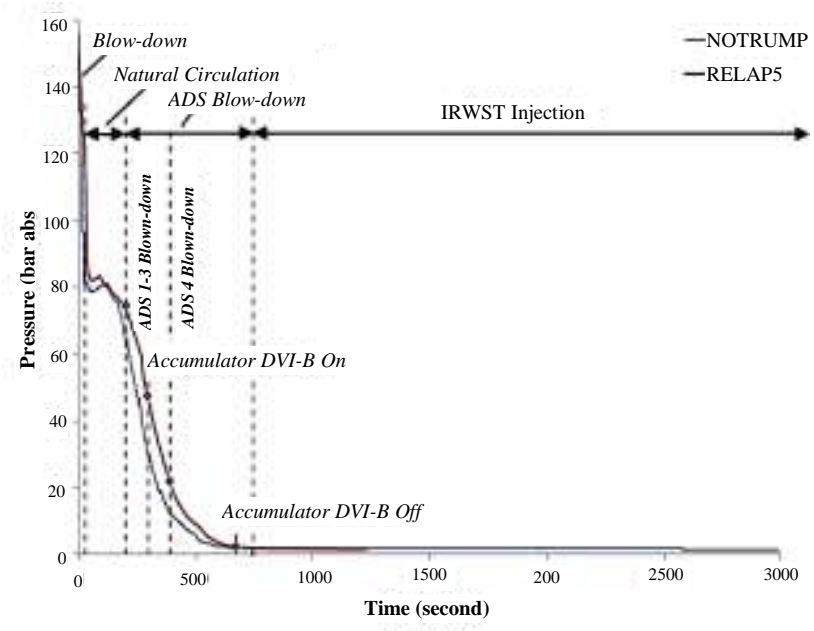

Fig. 5. RCS depressurization.
The RCS depressurization is caused by loss of inventory from the DVI-A line break and the downcomer (vessel side). Figure 6 shows the break flow rate from the downcomer (vessel side) calculated by RELAP5 and NOTRUMP codes. In the beginning, the NOTRUMP flowrate appears higher that the RELAP5, which might be caused by the differences in the loss coefficient of the break model. At the start of DVI break, only liquid flow discharges from the downcomer occurs, to be followed by steam flow as the void fraction in the core increases [18], as shown by NOTRUMP calculation results. That phenomenon (differences in the liquid and vapor phase of break flow) can not be shown in the present RELAP5 model. The RELAP5 calculation can only provide a combined liquid and vapor flow rate, where their distinct composition can be represented by the liquid or void fraction as indicated in the figure. The beginning of RELAP5 vapor break is characterized by the 0.5 void fraction in the break junction, meaning that the vapor break (junction liquid fraction less than 1.0) had occurred at an earlier point. The break flow transient from the vessel side after initiation of the break is then mainly influenced by the flow injection of CMT, accumulator, and IRWST in the intact DVI line into the core. When the core is supplied by the IRWST coolant, the break is more likely a mixture of watervapor as the junction's liquid fraction changes rapidly from 1.0 to 0.0 .

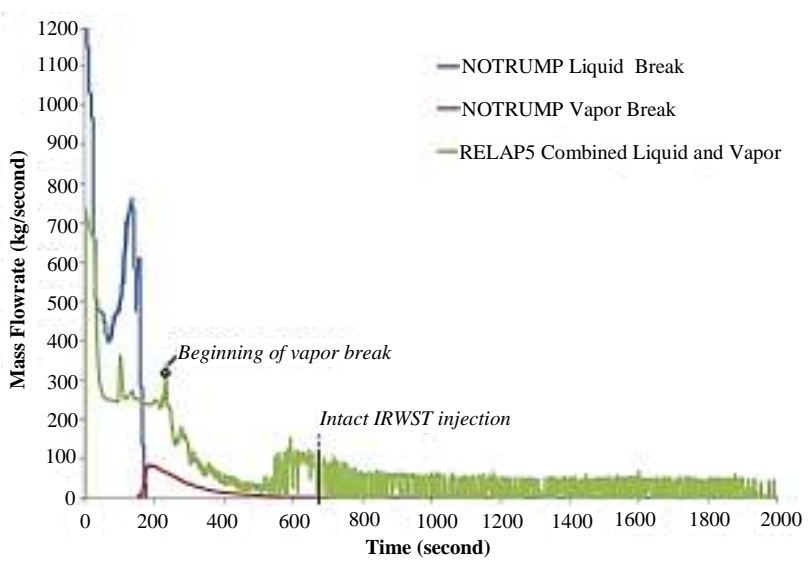

Fig. 6. Downcomer break discharge flowrate.

As previosly mentioned, the end of the blowdown phase is characterized by the occurrence of two-phase break flow and the emptying of the pressurizer, whose water is then replaced by steam. The emptiness of the pressurizer coincides with the CMT level decrease in the broken DVI line reaching the $67.5 \%$ level. This setpoint will actuate the opening of ADS stage 1, followed by stages 2 and 3 sequentially. Those ADS actuations result in a decrease of pressure at the pressurizer steam space and cause the coolant in the upper plenum to flow into the pressurizer [19]. This event is shown as an 
increase of the pressurizer's two-phase water level [20] until the actuation of the ADS stage 4 to drain the pressurizer water once more again. Figure 7 shows that increase and decrease of coolant inside the pressurizer due to the actuation of ADS valves.

The break occurrence in the DVI-A also directly initiates the coolant discharge from the accumulator as the line pressure suddenly drops below its nitrogen pressure. The flow is interrupted when the CMT isolation valve is opened to discharge coolant from the CMT as also shown in the increased break mass flow from broken DVI line. The aforementioned phenomena of accumulator and CMT flow are shown in Fig. 8 together with NOTRUMP calculation result for the CMT injection flow only, since the accumulator injection data for NOTRUMP in the DVI-A is not provided. In the CMT of the intact DVI line, a flow developed as a recirculation flow due to the density difference in the cold leg and the coolant inside the CMT, as shown in Fig. 9. In the figure, the stopped CMT flow due to the backpressure caused by high accumulator flowrate for RELAP5 calculation is visible [20] although the duration of the stoppage as found by the RELAP5 calculation results is shorter than what is found by the NOTRUMP calculation. By comparing the flow transient of Fig. 8 and Fig. 9, the break flow transient of Fig. 7 shows the influences of flow onset from accumulator and CMT.

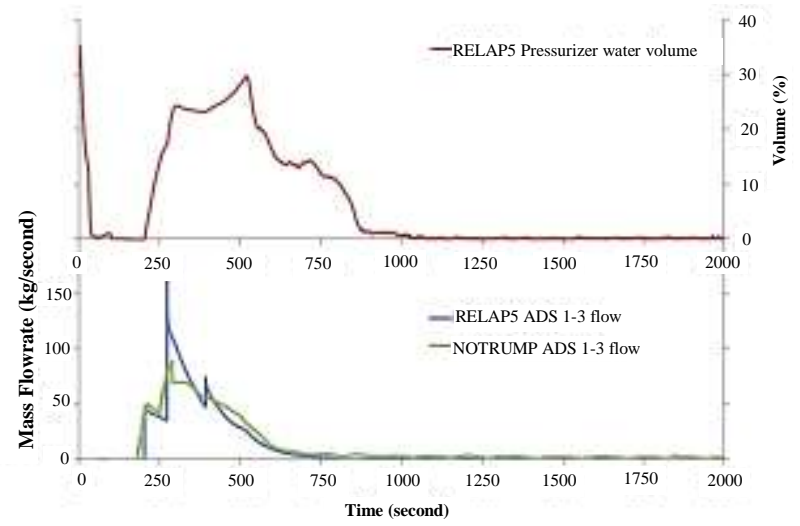

Fig. 7. Pressurizer water volume and ADS actuation flow rate.

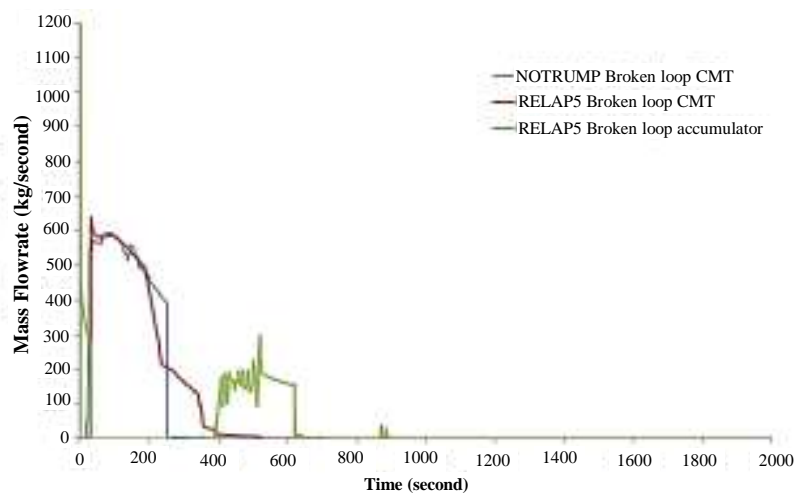

Fig. 8. CMT injection flowrate in the broken DVI line.

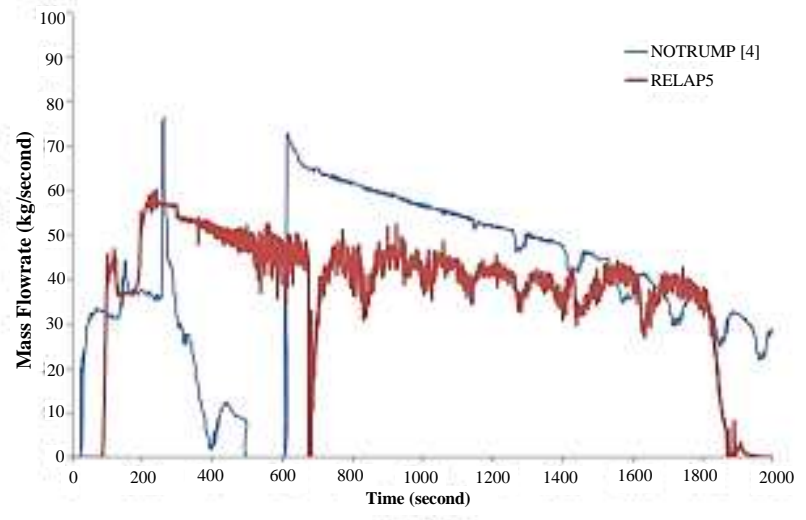

Fig. 9. CMT flowrate in the intact DVI line.

The comparison simulation results for coolant flow from accumulator of intact DVI line is shown in Fig. 10. From the figure, the calculated mass flowrates are similar for the RELAP5 and NOTRUMP code. The results indicate that the assumptions on the piping geometry in the accumulator model using RELAP5 are in line with the NOTRUMP model.

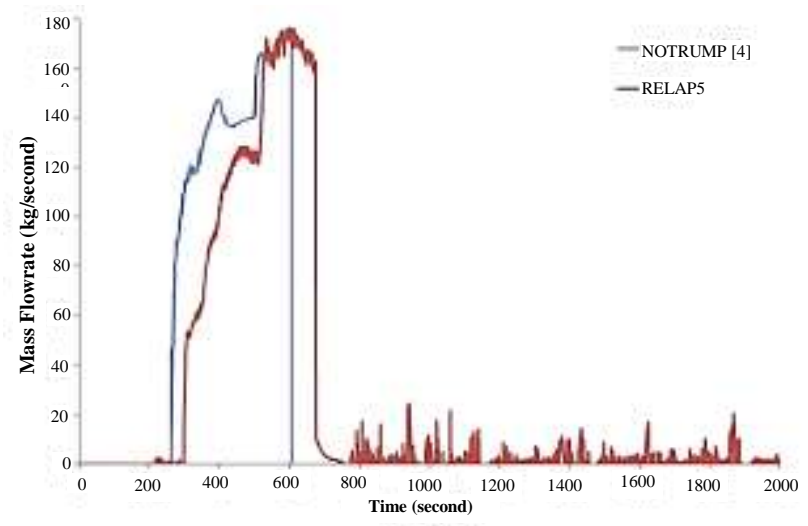

Fig. 10. Accumulator flowrate in the intact DVI line.

By analyzing the results of RELAP5 and NOTRUMP calculations, differences were found in the estimates of the discharge mass flowrate of the break and injection mass flowrate from accumulator or CMT. Those were again mainly caused by the effect of piping loss coefficient due to the model assumptions of the lengths and heights of the injection line and other lines in the DVI loops. In a natural circulation flow, a different height will result a different driving head and a different length means a different piping resistance, and those will affect the resulting mass flowrate along the pipe in the form of flow instability [21].

The sequenced actuation of ADS valves reduces the RCS pressure to a value that is below the IRWST pressure since it is directly connected to the containment. The IRWST injection line is isolated from the DVI line by a valve that opens 120 seconds after the actuation of ADS stage 3 or at the same time with the actuation of ADS stage 4 valves. The RCS depressurization via the ADS stage 
4 valves has the biggest impact on the reduction of RCS pressure to a value below the IRWST pressure. The valve opening will not lead directly to the IRWST water flow by gravity since the pressure in the connecting pipe of DVI line is still higher due to the CMT injection flow in the broken DVI line and the RCS pressure in the intact DVI line. As shown in Fig. 11, the IRWST injection flow starts to occur as the CMT volume is empty in the broken DVI line (see Fig. 8) and almost at the same time RCS pressure drops below the IRWST pressure in the intact DVI line. Compared with the NOTRUMP calculation, the IRWST gravity flow in the intact DVI line of RELAP5 is established earlier but stabilizes at the same flowrate of approximately 65 $\mathrm{kg} / \mathrm{s}$. The effect of loss coefficient and piping model in the IRWST injection line between the two codes might lead to the difference in the beginning of injection.

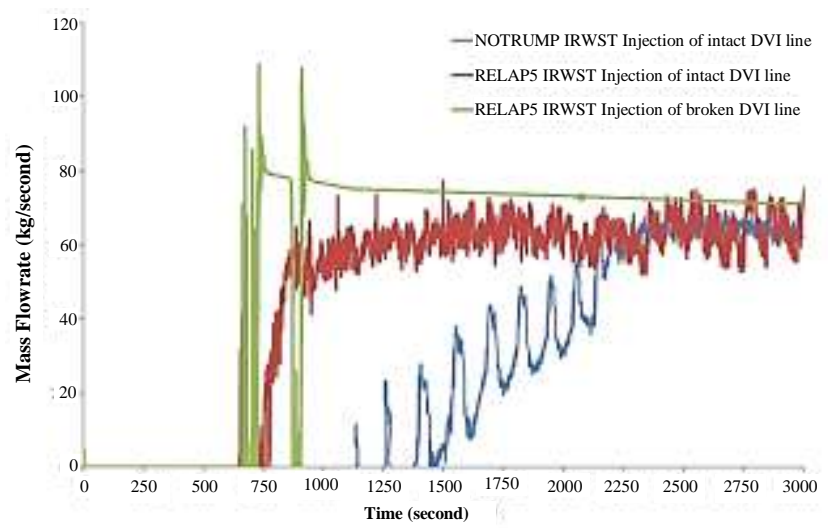

Fig. 11. IRWST injection flowrate in the broken and intact DVI lines.

The loss of RCS inventory due to the discharge from the break through the downcomer can be seen in the core mixture level as shown in Fig. 12. The core mixture level is caused by void formation under the two-phase mixture surface due to the boiling and flashing; in RELAP5, it is calculated by the equation below [22]

$$
H_{\text {mix }}=\frac{H_{\text {collapsed }}}{1-\alpha_{c}}
$$

Where $H_{\text {collapsed }}$ is the collapsed liquid level or the sum of all liquid fraction and $\alpha_{C}$ is the average void fraction along the axial components of related height. The mixture level is measured from the lower plenum, through the core, up to the upper plenum above it, resulting in the overall height of 8.46 meters. This result is close to the NOTRUMP calculation result of 8.84 meters in the normal (compressed) condition. Under the compressed condition, that mixture level is in reality a liquid (single) phase. By the same reference, the height of the active fuel is about 6.26 meters.

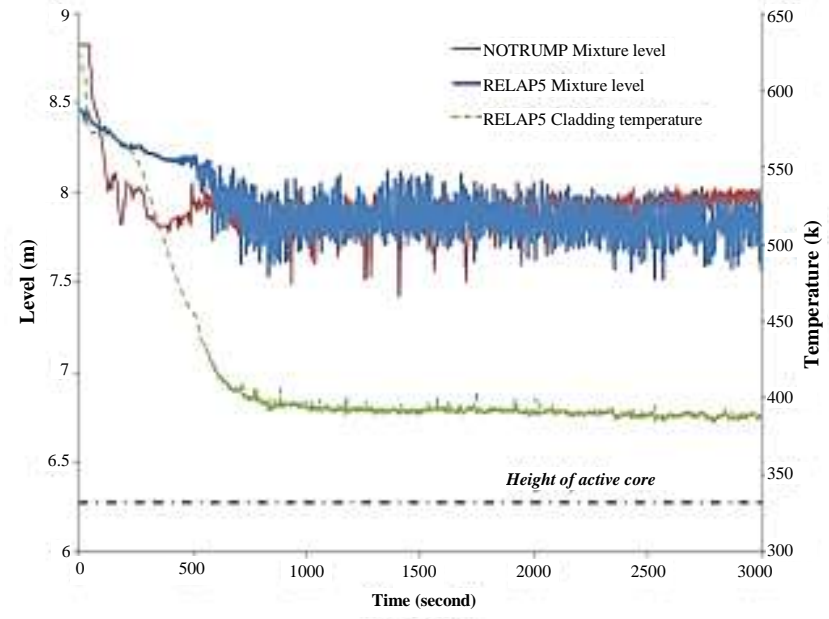

Fig. 12. Transient of core mixture level and cladding temperature.

Figure 12 shows the development of mixture level due to the loss of coolant inventory in the core region that, along the transient time, is still above the core height; thus, no core uncovery occurs. The core is cooled by the two-phase mixture [23] as proven by the cladding temperature reduction along the time. That result also conforms with the NOTRUMP calculation. The core uncovery event also emphasizes that the event of the DVI line break is included in the small-break LOCA category.

\section{CONCLUSION}

In this study, a double-ended break of DVI line in AP1000 was simulated and analyzed using RELAP5/SCDAP/Mod3.4. The results were compared with that obtained by NOTRUMP code as described in the AP1000 accident analysis document. By comparing the sequences of time, a relatively good agreement is found between the results of the two codes. From the comparison, it was also found that the results on several characteristics of injected flow from the passive safety system are also similar, as are the response of each passive component. The simulation results show that the break of one of two available DVI lines can be mitigated by the injected coolant flowing, which is operated effectively by gravity and by the density difference in the cooling system and does not lead to core uncovery. Despite the substantial effort to obtain an apropriate AP1000 model due to lack of detailed geometrical data, the present model can be used as a platform model for other initiating events considered in the AP1000 accident analysis. 


\section{ACKNOWLEDGEMENT}

This work was funded by an annual R\&D program of the Center for Nuclear Reactor Safety and Technology (PTKRN), National Nuclear Energy Agency of Indonesia. Therefore, the author also extend our sincere thank to the Head of the Center for supporting this work.

\section{REFERENCES}

1. Anonymous, World Statistics, Nuclear Energy around the World. http://www.nei.org. /Knowledge-Center/Nuclear-Statistics/WorldStatistics. Retrieved in 15 October (2014).

2. J.S. Wan, H.B. Song, S.J. Yan et al., Ann. Nucl. Energy 85 (2015) 704.

3. P.F. Wang, Y. Liu, B.T. Jiang et al., Ann. Nucl. Energy 62 (2013) 208.

4. M.G. Abdoelatef, R.M. Field and Y.K. Lee, Int. J. Chem. Mol. Nucl. Mater. Metall. Eng. 9 (2015) 1205 .

5. C. Queral and J. Montero-Mayorga, Ann. Nucl. Energy 91 (2016) 65.

6. Anonymous, AP1000 Design Control Document, Revision 17, Westinghouse Electric Company (2010).

7. X.D. Qiao, J.P. Jing, J.R. An et al., J. Comput. Math. Sci. Eng. 15 (2015) 63.

8. A. Elshahat, T. Abram, J. Hohorst et al., Int. J. Nucl. Energy 2014 (2014) ID 410715. doi:10.1155/2014/410715.

9. D. Lioce, M. Asztalos, A. Alemberti et al., Nucl. Eng. Des. 250 (2012) 538.

10. A.S. Ekariansyah, S. Widodo, Susyadi et al.,
J. Nucl. Reactor Tech. Tri Dasa Mega 13 (2011) 49. (in Indonesian).

11. A.S. Ekariansyah, S. Widodo, Susyadi et al., J. Nucl. Reactor Tech. Tri Dasa Mega 14 (2012) 76. (in Indonesian).

12. A.S. Ekariansyah and S. Widodo, Modelling on Passive Residual Heat Removal System Using Computer Code of RELAP5, Proceeding of the National Conference on Basic Science and Nuclear Technology (2011) 237. (in Indonesian).

13. A.S. Ekariansyah, S. Widodo and Susyadi, J. Nucl. Reactor Tech. Tri Dasa Mega 14 (2012) 137. (in Indonesian).

14. E.B. Shi, C.Y. Fang, C. Wang et al., Ann. Nucl. Energy 85 (2015) 590.

15. D.C. Sun, W.X. Tian, S.Z. Qiu et al., Prog. Nucl. Energy 74 (2014) 71.

16. Z. Guozhi, C. Xinrong and S. Xingwei, Res. J. Appl. Sci. Eng. Tech. 7 (2014) 18.

17. W.W. Wang, G.H. Su, S.Z. Qiu et al., Prog. Nucl. Energy 53 (2011) 407.

18. W.W. Wang, G.H. Su, S.Z. Qiu et al., Nucl. Eng. Des. 263 (2013) 380.

19. Y. Kukita, T. Yonomoto, H. Asaka et al., J. Nucl. Sci. Tech. 33 (1996) 259.

20. R.F. Wright, Nucl. Eng. Tech. 39 (2007) 287.

21. J.Y. Kudariyawar, A.M. Vaidya, N.K. Maheshwari et al., Int. J. Therm. Sci. 101 (2016) 193.

22. J. Yang, W.W. Wang, S.Z. Qiu et al., Ann. Nucl. Energy 46 (2012) 81.

23. T. Takeda, Int. J. Nucl. Energy 2014 (2014) ID 803470. doi: $10.1155 / 2014 / 803470$. 